\title{
FAKTOR-FAKTOR YANG BERHUBUNGAN DENGAN KEJADIAN PENYAKIT JANTUNG KORONER
}

\author{
Karyatin \\ Akademik Keperawan Sumber Waras \\ titinkaryatin61@gmail.com
}

\begin{abstract}
ABSTRAK
Penyakit Jantung Koroner (PJK) merupakan penyakit jantung yang terutama disebabkan karena penyempitan arteria koronaria akibat proses ateroskeloris atau spasme atau kombinasi keduanya, PJK terus menjadi penyebab utama kematian. Perubahan gaya hidup yang terjadi pada masyarakat membawa dampak terhadap perkembangan penyakit degenerative, salah satunya adalah PJK. Dampak utama PJK adalah gangguan pasokan oksigen dan nutrisi kedalam jaringan miokard akibat penurunan aliran darah coroner. Kemungkinan terjadinya PJK ditentukan oleh beberapa factor yaitu (1) faktor yang tidak dapat dirubah dantaranya usia, jenis kelamin, merokok, hipertensi, hiperkolesterol dan perilaku olah raga, (2) factor yang dapat dirubah yaitu perubahan gaya hidup. Penelitian ini bertujuan untuk mengetahui factor-faktor yang berhubungan dengan kejadian PJK di Rumah Sakit Sumber Waras Jakarta. Jenis penelitian kuantitatif yang bersifat analitik yaitu menggunakan metode penelitian cross sectional, jumlah sampel 40 orang dengan accidental sampling. Penelitian ini dilakukan hanya 1 kali selama pasien dirawat. Hasil penelitian membuktikan bahwa ada hubungan antara perilaku olah raga dengan kejadian PJK dengan didapatkan nilai $\mathrm{p}$ value : 0,020. Nilai olah raga yang diperoleh sebesar 6,333 yang berarti bahwa perilaku olah raga yang kurang baik memiliki resiko 6 kali lebih besar untuk terjadi penyakit jantung coroner bila dibandingkan dengan perilaku olah raga yang baik.
\end{abstract}

Kata kunci : Faktor-faktor, Penyakit Jantung Koroner

\section{PENDAHULUAN}

Penyakit jantung coroner (PJK) ialah penyakit jantung yang terutama disebabkan karena penyempitan arteria koronaria akibat proses aterosklerosis atau spasme atau kombinasi keduanya. PJK terus menjadi penyebab utama kematian diantara individu orang-orang dewasa di Australia dan Selandia Baru, keadaan ini tetap berlanjut sekalipun terjadi peningkatan dalam pencegahan dan penanganan penyakit (Esther,2009).

Perubahan gaya hidup yang terjadi pada masyarakat membawa dampak terhadap perkembangan penyakit degeneratif, salah satunya adalah PJK. WHO memperkirakan sekitar 17 juta orang meninggal akibat penyakit kardiovaskuler, pada tahun 2005 sekitar 7,6 juta meninggal dunia akibat PJK. Penyakit ini merupakan salah satu masalah kesehatan utama yang banyak diderita oleh masyarakat diseluruh dunia termasuk Indonesia. WHO memperkirakan sekitar 17 juta orang meninggal akibat penyakit kardiovaskuler, setiap 5 detik satu orang meninggal akibat serangan jantung. Sekitar $80 \%$ dari kematian tersebut terjadi di negara-negara berpendapatan rendah dan menengah.

Di Amerika setiap tahunnya 550 orang meninggal karena PJK. Hasil survey yang dilakukan Departemen Kesehatan RI menyatakan prevalensi PJK di Indonesia dari tahun ke tahun terus meningkat (Majid,2007). Dampak utama PJK adalah gangguan pasokan oksigen dan nutrisi ke dalam jaringan miokard akibat penurunan aliran darah coroner. Kurangnya pasokan darah karena penyempitan arteri coroner mengakibatkan gejala angina.

Angina pectoris merupaka suatu sindrom klinis didapatkan sakit dada yang timbul waktu melakukan aktivitas karena adanya iskemik miokard. Hal ini menunjukan telah terjadi $>70 \%$ penyempitan arteria koronaria. Angina 
pectoris dapat muncul sebagai angina pectoris stabil (APS) dan dapat berkembang menjadi lebih berat yaitu Sindroma KOroner Akut (SKA) atau dikenal dengan serangan jantung mendadak (heart attack) dan menyebabkan kematian (Majid,2007).

Hasil survey yang dilakukan Departemen Kesehatan Republik Indonesia menyatakan prevalensi menunjukan PJK menempati peringkat ke 3 penyebab kematian setelah stroke dan hipertensi. Angka kejadian PJK berdasarkan data Riset Kesehatan Dasar (Riskesdas) Kemenkes pada tahun 2007 adalah sebanyak 7,2\% (Azahra,2011). Fakta menunjukan bahwa PJK menyumbang 40\% dari seluruh kematian, sebanyak 17 juta kasus didiagnosa baru PJK tercatat setiap tahunnya. Berdasarkan data dari Rumah Sakit Sumber Waras, kasus PJK dari tahun ke tahun cenderung meningkat, tahun 2011 sebanyak 41 kasus dan tahun 2012 terdapat 87 kasus PJK. Kemungkinan terjadinya PJK ditentukan oleh factor tertentu, yaitu factor yang tidak dapat dirubah dan factor yang dapat dirubah melalui perubahan gaya hidup. Faktor yang tidak dapat diubah yaitu umur, jenis kelamin, ras dan factor herediter.Sedangkan factor yang dapat dirubah yaitu hiperkolesterolemia, hipertensi, rokok, banyak makan lemak, kurang olah raga, stress dan obesitas (Tambayong,2012).

Berdasarkan latar belakang maka rumusan masalahnya adalah "Faktor-faktor apa sajakah yang berhubungan dengan kejadian PJK di Rumah Sakit Sumber Waras tahun 2013", dan penelitian ini bertujuan untuk mengetahui factor-faktor yang berhubungan dengan kejadian PJK.

\section{METODE PENELITIAN}

Jenis penelitian non eksperimen dengan rancangan cross sectional yang menekankan waktu pengukuran/observasi data variable independen dan dependen hanya satu kali pada satu saat (Nursalam, 2011 hal 83). Populasi dalam penelitian ini adalah seluruh pasien PJK yang berobat di ruang rawat Rumah Sakit Sumber Waras berjumlah 25 orang dengan tehnik pengampilan sampel secara tot sampling, dan dilakukan selama periode Oktober - Desember 2012. Adapun kriteria sampel antara lain : (1) kriteria inklusi ; pasien PJK dengan usia > 20 tahun, pasien PJK tanpa komplikasi, bersedia menjadi responden. Sedangkan (2) kriteria eklusi ; pasien PJK dengan komplikasi (DM, CVD), pasien yang tidak bersedia berpartisipasi dalam penelitian. Pengumpulan data dilakukan dengan menggunakan lembar kuesioner dan lembar observasi. Lembar kuesioner terkait usia, jenis kelamin, riwayat perokok, perilaku olah raga, kadar kolesterol dan PJK. Lembar observasi terkait hipertensi.

\section{HASIL PENELITIAN}

Hasil penelitian didasarkan pada analisa univariat dan bivariate. Analisis hasil penelitian univariat yaitu : usia, jenis kelamin, merokok, perilaku olah raga, hipertensi, kadar kolesterol, PJK, hasil data kategorik disajikan dalam bentuk distribusi frekuensi.

Analisis bivariate untuk membuktikan hipotesis penelitian terhadap factor-faktor yang berhubungan dengan kejadian PJK.

Tabel 1 dibawah menunjukan bahwa kejadian PJK banyak terjadi pada usia lebih dari 35 tahun $(72,4 \%)$ dibandingkan dengan usia kurang dari 35 tahun (27,3\%). Hasil uji statistic didapatkan nilai p value: 0,009 dapat 
disimpulkan ada hubungan antara usia dengan kejadian PJK di ruang rawat inap Rumah Sakit Sumber Waras Jakarta. Nilai OR yang diperoleh sebesar 0,143 yang berarti bahwa usia lebih dari 35 tahun memiliki resiko 0,143 kali lebih besar untuk terjadi penyakit jantung coroner bila dibandingkan dengan usia kurag dari 35 tahun.

\section{Tabel 1}

Hubungan antara usia dengan kejadian Penyakit Jantung Koroner di Ruang Rawat Inap Rumah Sakit Sumber Waras

\begin{tabular}{|c|c|c|c|c|c|}
\hline \multirow[b]{2}{*}{ Usia } & \multicolumn{2}{|c|}{$\begin{array}{c}\text { Kejadian Penyakit Jantung } \\
\text { Koroner }\end{array}$} & \multirow[b]{2}{*}{ Total } & \multirow[b]{2}{*}{$P$ Value } & \multirow[b]{2}{*}{$\begin{array}{c}\text { OR } \\
(95 \% \mathrm{CI})\end{array}$} \\
\hline & PJK & Tidak PJK & & & \\
\hline $20-35$ tahun & $\begin{array}{c}3 \\
273 \%\end{array}$ & $\begin{array}{c}8 \\
727 \%\end{array}$ & 11 & 0.009 & $\begin{array}{c}0,14 \\
0,030\end{array}$ \\
\hline$>35$ tahun & $\begin{array}{c}21 \\
72,4 \%\end{array}$ & $\begin{array}{c}8 \\
27,6 \%\end{array}$ & $\begin{array}{c}29 \\
100 \%\end{array}$ & & $0,678)$ \\
\hline Total & $\begin{array}{c}24 \\
60,0 \%\end{array}$ & $\begin{array}{c}16 \\
40,0 \%\end{array}$ & $\begin{array}{c}40 \\
100 \%\end{array}$ & & \\
\hline
\end{tabular}

Tabel 2 dibawah menunjukan bahwa kejadian PJK banyak terjadi pada jenis kelamin laki-laki (79,2\%) bila dibandingkan dengan jenis kelamin perempuan (31,3\%). Hasil uji statistic di dapatkan nilai p value 0,0007 maka dapat disimpulkan ada hubungan antara jenis kelamin dengan kejadian PJK di ruang rawat inap Rumah Sakit Sumber Waras. Nilai OR yang diperoleh sebesar 8,360 yang berarti bahwa jenis kelamin laki-laki memiliki resiko 8 kali lebih besar untuk terjadi penyakit jantung coroner bila dibandingkan dengan jenis kelamin perempuan.

Tabel 2

Hubungan antara jenis kelamin dengan kejadian Penyakit Jantung Koroner di Ruang Rawat Inap Rumah Sakit Simber Waras

\begin{tabular}{|c|c|c|c|c|c|}
\hline \multirow[b]{2}{*}{ Jenis kelamin } & \multicolumn{2}{|c|}{$\begin{array}{c}\text { Kejadian Penyakit Jantung } \\
\text { Koroner } \\
\end{array}$} & \multirow[b]{2}{*}{ Total } & \multirow[b]{2}{*}{ P Value } & \multirow[b]{2}{*}{$\begin{array}{c}\text { OR } \\
(95 \% \mathrm{CI})\end{array}$} \\
\hline & PJK & Tidak PJK & & & \\
\hline Laki-laki & $\begin{array}{l}19 \\
79,2 \%\end{array}$ & $\begin{array}{l}5 \\
20,8 \%\end{array}$ & 24 & 0.007 & $\begin{array}{l}8,360 \\
(1,971-\end{array}$ \\
\hline Perempuan & $\begin{array}{l}5 \\
31,3 \% \\
\end{array}$ & $\begin{array}{l}11 \\
68,8 \%\end{array}$ & $\begin{array}{l}16 \\
100 \%\end{array}$ & & $35,461)$ \\
\hline Total & $\begin{array}{l}24 \\
60,0 \%\end{array}$ & $\begin{array}{l}16 \\
40,0 \%\end{array}$ & $\begin{array}{l}40 \\
100 \%\end{array}$ & & \\
\hline
\end{tabular}

Sumber data :Data Primer Diolah

Tabel 3 dibawah menunjukan bahwa kejadian PJK banyak terjadi karena merokok $(78,9 \%)$ bila dibandingkan dengan tidak merokok (42,9\%). Hasil uji statistic didapatkan nilai p value 0,045, maka dapat disimpulkan bahwa ada hubungan antara merokok dengan kejadian PJK di ruang rawat inap Rumah Sakit Sumber Waras. Nilai OR yang diperoleh sebesar 5 yang berarti bahwa merokok memiliki resiko 5 kali lebih besar untuk terjadi penyakit jantung coroner bila dibandingkan dengan tidak merokok. 
Tabel 3

Hubungan antara merokok dengan kejadian Penyakit Jantung Koroner di Ruang Rawat Inap Rumah Sakit Sumber Waras

\begin{tabular}{|c|c|c|c|c|c|}
\hline \multirow[b]{2}{*}{ Merokok } & \multicolumn{2}{|c|}{$\begin{array}{c}\text { Kejadian Penyakit Jantung } \\
\text { Koroner }\end{array}$} & \multirow[b]{2}{*}{ Total } & \multirow[b]{2}{*}{ P Value } & \multirow[b]{2}{*}{$\begin{array}{c}\text { OR } \\
(95 \% \mathrm{CI})\end{array}$} \\
\hline & PJK & Tidak PJK & & & \\
\hline \multirow[t]{2}{*}{ Merokok } & 15 & 4 & \multirow[t]{2}{*}{19} & \multirow[t]{4}{*}{0.045} & 5,000 \\
\hline & $78,9 \%$ & $21,1 \%$ & & & $(1,231-$ \\
\hline \multirow[t]{2}{*}{ Tidak merokok } & 9 & 12 & \multirow{2}{*}{$\begin{array}{l}21 \\
100 \% \\
\end{array}$} & & $20,301)$ \\
\hline & $42,9 \%$ & $57,4 \%$ & & & \\
\hline \multirow[t]{2}{*}{ Total } & 24 & 16 & \multirow{2}{*}{\multicolumn{2}{|c|}{$\begin{array}{l}40 \\
100 \%\end{array}$}} & \\
\hline & $60,0 \%$ & $40,0 \%$ & & & \\
\hline
\end{tabular}

Sumber Data : Data Primer diolah.

Tabel 4 menunjukan bahwa kejadian PJK banyak terjadi karena hipertensi $(81,8 \%)$ bila dibandingkan dengan tidak hipertensi $(33,3 \%)$. Hasil uji statistic di dapatkan nila $p$ value 0,0005 , maka dapat disimpulkan bahwa ada hubungan antara hipertensi dengan kejadian PJK di ruang rawat inap Rumah Sakit Sumber Waras. Nilai OR yang diperoleh sebesar 9 yang berarti bahwa hipertensi memiliki resiko 9 kali lebih besar untuk terjadi penyakit jantung coroner bila dibandingkan tidak hipertensi

Tabel 4

Hubungan antara hipertensi dengan kejadian PJK di ruang rawat inap Rumah Sakit Sumber Waras

\begin{tabular}{|c|c|c|c|c|c|}
\hline \multirow[b]{2}{*}{ Hipertensi } & \multicolumn{2}{|c|}{$\begin{array}{c}\text { Kejadian Penyakit Jantung } \\
\text { Koroner }\end{array}$} & \multirow[b]{2}{*}{ Total } & \multirow[b]{2}{*}{ P Value } & \multirow[b]{2}{*}{$\begin{array}{c}\text { OR } \\
(95 \% \mathrm{CI})\end{array}$} \\
\hline & PJK & Tidak PJK & & & \\
\hline Hipertensi & $\begin{array}{l}18 \\
81,8 \%\end{array}$ & $\begin{array}{l}4 \\
18,2 \%\end{array}$ & 22 & 0.005 & $\begin{array}{l}9,000 \\
(2,088-\end{array}$ \\
\hline $\begin{array}{l}\text { Tidak } \\
\text { hipertensi }\end{array}$ & $\begin{array}{l}6 \\
33,3 \% \\
\end{array}$ & $\begin{array}{l}12 \\
66,7 \% \\
\end{array}$ & $\begin{array}{l}18 \\
100 \%\end{array}$ & & $38,787)$ \\
\hline Total & $\begin{array}{l}24 \\
60,0 \%\end{array}$ & $\begin{array}{l}16 \\
40,0 \%\end{array}$ & $\begin{array}{l}40 \\
100 \%\end{array}$ & & \\
\hline
\end{tabular}

Sumber Data : Data Primer Diolah

Tabel 5 menunjukan bahwa kejadian PJK banyak terjadi pada hiperlipid $(82,4 \%)$ bila dibandingkan dengan normolipid (43,5\%). Hasil uji statistic di dapatkan nilai p value 0,031, maka dapat disimpulkan ada hubungan antara kadar kolesterol dengan kejadian PJK di ruang rawat inap Rumah Sakit Sumber Waras. Nilai OR yang diperoleh sebesar 6,067 yang berarti bahwa kadar kolesterol yang tinggi memiliki resiko 6 kali lebih besar untuk terjadi penyakit jantung coroner bila dibandingkan dengan kadar kolesterol normal. 
Tabel 5

Hubungan antara kadar kolesterol dengan kejadian PJK di ruang rawat inap Rumah Sakit Sumber Waras

\begin{tabular}{|c|c|c|c|c|c|}
\hline \multirow[b]{2}{*}{$\begin{array}{c}\text { Kadar } \\
\text { kolesterol }\end{array}$} & \multicolumn{2}{|c|}{$\begin{array}{c}\text { Kejadian Penyakit Jantung } \\
\text { Koroner }\end{array}$} & \multirow[b]{2}{*}{ Total } & \multirow[b]{2}{*}{ P Value } & \multirow[b]{2}{*}{$\begin{array}{c}\text { OR } \\
(95 \% \mathrm{CI})\end{array}$} \\
\hline & PJK & Tidak PJK & & & \\
\hline \multirow[t]{2}{*}{ Hiperlipid } & 14 & 3 & 17 & 0.031 & \multirow{4}{*}{$\begin{array}{l}6,067 \\
(1,361- \\
27,049)\end{array}$} \\
\hline & $82,4 \%$ & $17,6 \%$ & & & \\
\hline \multirow[t]{2}{*}{ Normolipid } & 10 & 13 & 23 & & \\
\hline & $43,5 \%$ & $56,5 \%$ & $100 \%$ & & \\
\hline \multirow[t]{2}{*}{ Total } & 24 & 16 & 40 & & \\
\hline & $60,0 \%$ & $40,0 \%$ & $100 \%$ & & \\
\hline
\end{tabular}

Sumber Data : Data Primer Diolah.

Tabel 6

Hubungan antara perilaku Olah Raga dengan kejadian Penyakit Jantung Koroner di ruang rawat inap Rumah Sakit Sumber Waras

\begin{tabular}{|c|c|c|c|c|c|}
\hline \multirow[b]{2}{*}{$\begin{array}{c}\text { Perilaku olah } \\
\text { raga }\end{array}$} & \multicolumn{2}{|c|}{$\begin{array}{c}\text { Kejadian Penyakit Jantung } \\
\text { Koroner }\end{array}$} & \multirow[b]{2}{*}{ Total } & \multirow[b]{2}{*}{$P$ Value } & \multirow[b]{2}{*}{$\begin{array}{c}\text { OR } \\
(95 \% \mathrm{CI})\end{array}$} \\
\hline & PJK & Tidak PJK & & & \\
\hline \multirow[t]{2}{*}{ Kurang baik } & 19 & 6 & \multirow[t]{2}{*}{25} & \multirow[t]{4}{*}{0.020} & 6,333 \\
\hline & $76,0 \%$ & $24,0 \%$ & & & $(1,543-26-$ \\
\hline \multirow[t]{2}{*}{ Baik } & 5 & 10 & \multirow{2}{*}{$\begin{array}{l}23 \\
100 \%\end{array}$} & & 003) \\
\hline & $33,3 \%$ & $66,7 \%$ & & & \\
\hline \multirow[t]{2}{*}{ Total } & 24 & 16 & \multicolumn{2}{|l|}{40} & \\
\hline & $60,0 \%$ & $40,0 \%$ & \multicolumn{2}{|l|}{$100 \%$} & \\
\hline
\end{tabular}

Sumber Data : Data Primer Diolah

Tabel 6 menunjukan bahwa kejadian Penyakit Jantung Koroner banyak terjadi pada pasien yang berperilaku olah raga kurang baik $(76,0 \%)$ bila dibandingkan dengan perilaku olah raga yang baik $(33,3 \%)$. Hasil uji statistic di dapatkan nilai $\mathrm{p}$ value 0,020 , maka dapat disimpulkan bahwa ada hubungan antara perilaku olah raga dengan kejadian PJK di ruang rawat inap Rumah Sakit Sumber Waras. Niai OR yang diperoleh sebesar 6,333 yang berarti bahwa perilaku olah raga yang kurang baik memiliki resiko 6 kali lebih besar untuk terjadi penyakit jantung coroner bila dibandingkan dengan perilaku olah raga yang baik.

\section{PEMBAHASAN}

Ada perbedaan jumlah responden di proposal dan hasil penelitian, saat penyusunan proposal peneliti mendapatkan jumlah responden PJK yang dirawat periode Oktober sampai dengan Desember 2012 sebanyak 25 orang, tetapi pada saat dilakukan penelitian jumlah responden bertambah menjadi 40 orang, hal ini menunjukan adanya peningkatan jumlah kejadian PJK. Hasil analisis menunjukan bahwa kejadian PJK banyak terjadi pada 
usia > 35 tahun dengan hasil uji statistic p value: 0,009 ini menunjukan ada hubungan antara usia dengan kejadian PJK, karena dengan bertambahnya usia kadar kolesterol baik laki-laki maupum perempuan mulai meningkat (Djohan,2004). Kejadian PJK banyak terjadi pada jenis kelamin laki-laki dengan hasil p value: 0,007 ini menunjukan bahwa ada hubungan antara jenis kelamin dengan kejadian PJK, karena pada wanita premenopause efek perlindungan esterogen penyakit jantung aterosklerotik yang lebih rendah dan memiliki konsentrasi HDL yang lebih tinggi arastuti,2009, Sherwood,2003). Kejadian PJK juga banyak terjadi karena hipertensi dengan hasil $\mathrm{p}$ value 0,005 ini menunjukan bahwa ada hubungan antara penyakit hipertensidengan kejadian PJK, karena adanya perubahan struktur arteri dan arterial sistemik, terutama terjadi pada kasus-kasus yang tidak diobati. Mula-mula terjadi hipertropi pada tunika media lalu diikuti dengan hialinisasi setempat dan penebalan fibrosis dari tunika intima, akhirnya akan terjadi penyempitan pembuluh darah (Djohan, 2004). Kejadian PJK banyak terjadi pada hiperlipid dengan hasil $\mathrm{p}$ value 0,031 ini menunjukan ada hubungan antara kadar kolesterol dengan kejadian PJK, kadar kolesterol darah dipengaruhi oleh susunan makanan sehari-hari yang masuk dalam tubuh. Penelitian epidemiologi klinik dan patologi jelas membuktikan peranan primer dyslipidemia dalam aterogenesis merupakan salah satu resiko utama terhadap penyakit kardiovaskuler. Kejadian PJK banyak terjadi pada pasien yang berperilaku olah raga kurang baik dengan hasil $\mathrm{p}$ value 0,020 ini menunjukan bahwa ada hubungan antara perilaku olah raga dengan kejadian PJK, intinya dengan olah raga 1-3 kali seminggu sudah cukup dengan pemanasan dan senam ringan sekitar 5 menit hingga berkeringat. Para peneliti di Harvad menemukan penurunan resiko penyakit jantung sampai $20 \%$ pada orang yang paling sering melakukan olah raga berat, berjalan sejauh 3 mil dalam seminggu dapat mengurangi penyakit jantung dan pembuluh darah sebesar 10\%. Sebuah penelitian di Jerman juga menemukan bahwa orang yang berolah raga secara teratur seumur hidupnya memiliki kemungkinan 60\% lebih kecil terkena PJK dari pada orang yang banyak duduk (Gustina, 2012).

\section{KESIMPULAN DAN REKOMENDASI}

Berdasarkan uraian tersebut diatas maka dapat disimpulkan bahwa kejadian PJK sangat dipengaruhi oleh beberapa factor diantaranya usia, jenis kelamin, hipertensi, kadar kolesterol, perilaku olahraga dan merokok. Modifikasi gaya hidup untuk mengurangi progresivitas PJK, modifikasi ini meliputi penghentian kebiasaan merokok, latihan teratur, manajemen stress, upaya mempertahankan berat badan yang ideal dan diet rendah lemak serta garam (Kowalak, 2007).

Untuk mencegah kejadian PJK adalah berperilaku sehat dengan tidak merokok, olah raga secara teratur, makan makanan yang sehat dan konsumsi kolesterol yang seimbang serta tidak stress. Khususnya bagi penderita DM, disarankan minum obat anti diabetes secara rutin sesuai dosis yang dianjurkan, makanan sesuai dengan pola diet DM, olah raga secara teratur dapat meningkatkan efektifitas kerja insulin, mengontrol berat badan, memperkuat kerja jantung dan mengurangi stress. 


\section{REFERENSI}

1. Chang, E. Dkk. 2009. Patofisiologi, Aplikasi Pada praktik Keperawatan. Jakarta EGCD.

2. Diknas, 2005. Kamus Besar Bahasa Indonesia Edisi Ketiga. Jakarta: Balai Pustaka.

3. Djohan, T.B.A. 2004. Penyakit JantungKoroner dan Hipertensi. Dalam: USU e-Repository (02004 Universitas Sumatera Utara, http://library.usu.ac.id/download/fk/gizi-bahri 10.pdf diakses pada hari: Senin 15 April 2013.

4. Gustin, I. 2012. Olahraga Adalah Cara Terbaik Mencegah Penyakit Jantung. http://healt.detik.com/read/olahraga-adalah-cara-terbaik-mencegah.html diakses pada tanggal 20 Mei 2013.

5. Hastono, S.P. 2007. Analisis Data Kesehatan. Jakarta: Fakultas Kesehatan Masyarakat Universitas Indonesia.

6. Hidayat, A.A.A. 2011. Metode Penelitian Keperawatan dan Teknik Analisis. Data, Jakarta: Salemba Medika.

7. Kowalak, J.P. Dkk. 2011. Buku Ajar Patofisiologi. Jakarta: EGC.

8. Majid, A. 2007. Penyakit Jantung Koroner: Patofisiologi, Pencegahan dan Pengobatan Terkini. Dalam: USU e-Repository @2008 Universitas Sumatera Utara http://library.usu.ac.id/download/fk/PJK.pdf di akses pada hari senin 15 April 2013.

9. Notoatmodjo, S. 2010. Metodologi Penelitian Kesehatan. Jakarta: PT. Rineka Cipta.

10. Ridwan, M. 2006. Mengenal, Mencegah, mengatasi Silent Killer Jantung Koroner. Semarang: Pustaka Widyamara.

11. Robbins, S.L.Dkk. 2007. Buku Ajara Patologi. Jakarta EGC.

12. Sarastuti, A.W. 2009. Pervalensi Penderita PJK Dengan Kadar Kolesterol HDL Rendah Di RS. Jantung Binawaluya Selama Tahun 2008-2009. http://perpus.fkik.uinjkt.ac.id/file digital/Arum\%20Widi\%20Sarastuti.pdf. Diaskes pada hari Senin 15 April 2013.

13. Setiawan, E. 2012. Kamus Besar Bahasa Indonesia. Jakarta: Hak Cipta Badan Pengembangan dan Pembinaan Bahas, Kemdikbud. Dalam : KBBI Online http://kbbi.web.id diaskes pada tanggal 10 Mei 2013.

14. Tambayong, J. 2012. Patofisiologi Untuk Keperawatan. Jakarta: EGC. 